\title{
LUZ, SOMBRA E AFETOS: 'QUASE-MEMÓRIA' DA VISITA DO FOTÓGRAFO JOÃO ROBERTO RIPPER A PONTA GROSSA (PR)
}

\section{LIGHT, SHADOW AND AFECTS: 'ALMOST- MEMORY’ OF PHOTOGRAPHER JOÃO ROBERTO RIPPER'S COMING TO PONTA GROSSA}

\author{
Rafael Schoenherr" \\ Manoel Moabis*** \\ Saori Honorato \\ Veridiane Parize
}

RESUMO: O artigo relembra a participação do fotodocumentarista João Roberto Ripper no Ciclo Comemorativo aos 50 anos de maio de 1968, na Universidade Estadual de Ponta Grossa. Com base na palestra, o texto estimula debate sobre modos de ver, agir e narrar presentes no modo de produção do fotojornalista e que, eventualmente, estabelecem sintonias possíveis para com as transformações culturais herdadas daquele período. Destaca-se, sobretudo, o modo particular como o trabalho do fotógrafo estabelece um registro documental e jornalístico em fotos sobre os direitos humanos no Brasil. PalaVRAS-CHAVE: fotojornalismo; documentarismo; direitos humanos.

AвSTRACT: The article recalls the participation of the photocumentarist João Roberto Ripper in the Commemorative Cycle at the 50th anniversary of May 1968, at Ponta Grossa State University. Based on the lecture, the text stimulates debate about ways of seeing, acting and narrating present in the photojournalist's mode of production and that eventually establish possible attunements to the cultural transformations inherited from that period. Particularly noteworthy is the particular way in which the

\footnotetext{
"Jornalista. Doutor em Geografia pela UEPG, coordenador do projeto de extensão Lente Quente. Mestre em Ciências da Comunicação pela Unisinos. Professor do Departamento de Jornalismo da UEPG. Email: rafaelschoenherr@gmail.com "Jornalista. Doutorando em Ciências da Comunicação pela Unisinos. Mestre em Jornalismo pela UEPG. Supervisor do projeto de extensão Lente Quente. Professor do Departamento de Jornalismo da UEPG. Email: manoelmoabis@ hotmail.com

***t Graduanda em Jornalismo na UEPG, bolsista PIBIS do projeto Lente Quente. Email: saorihonorato@gmail.com

"naw* Graduanda em Jornalismo na UEPG, bolsista PIBIS do projeto Foto Bianchi. Email: veridianeparize@hotmail.com
} 
photographer's work establishes a documentary and journalistic record in human rights photographs in Brazil.

KEYwORDs: photojournalism; documentaryism; human rights.

\section{ECOS VISUAIS DE 68: APROXIMAÇõES ENTRE RIPPER E O CICLO COMEMORATIVO}

O fotógrafo João Roberto Ripper, um dos maiores documentaristas brasileiros, esteve em Ponta Grossa (PR) entre os dias 26 e 27 de junho de 2018 para participar do Ciclo Comemorativo 50 Anos em Movimentos, série de encontros e debates na Universidade Estadual de Ponta Grossa (UEPG) - estendida a outros espaços da cidade - alusiva ao maio de 1968 e suas repercussões nas décadas seguintes pelo mundo. O fotojornalista ministrou a palestra 'Fotografia de Resistência: Imagens em Defesa dos Direitos Humanos', evento viabilizado pela parceria entre o Programas de Pós-Graduação de Jornalismo e de Educação da instituição, com apoio da Fundação Municipal de Cultura. A organização da visita ficou por conta do projeto de extensão Lente Quente, do curso de Jornalismo, voltado à produção fotojornalística em cultura.

A exemplo de outros ciclos comemorativos que aconteceram durante o ano pelo país, parte da motivação do evento local era rememorar os 50 anos do maio de 1968 francês e europeu para um esforço de repensar os movimentos sociais no Brasil e as possibilidades de resistência frente a recentes cenários de recrudescimento na seara dos direitos sociais, das instâncias democráticas, de liberdades individuais e coletivas - com reais impactos sobre as práticas expressivas, o acesso à informação e os espaços do jornalismo. A vinda de Ripper contribui para esse balanço e para inserir a temática da fotografia (e do olhar) em tais reflexões - tópico pouco contemplado em eventos congêneres, em que pesa o crescente apelo visual das manifestações daquele período, que se estendeu e se intensificou nas décadas seguintes na forma de uma cultura da imagem (como já antecipavam os situacionistas).

Nesse sentido, o intuito do presente ensaio, na forma de 'quase-memória', é o de registrar e reconhecer a contribuição da fala do fotógrafo em 26 de junho' para o já mencionado campo de debates do evento. Busca-se, sobretudo, pistas para a descrição de um pensamento/ modo de fazer específico, mobilizado em terreno pelo profissional no tocante à visibilidade dos direitos humanos no Brasil. Fica evidente que essa não é uma questão automática, onde bastaria a intenção do profissional da comunicação ou do jornalismo para se ter um retrato dos direitos humanos no Brasil. O texto pretende justamente deixar claro todo o movimento e repertório particular organizadores do olhar do fotógrafo.

O convidado disserta sobre seu próprio trabalho, e é a partir dessa representação do fazer fotográfico que se quer acessar: (a) possíveis reverberações (contra)culturais inscritas

\footnotetext{
${ }^{1}$ A palestra na íntegra foi transmitida ao vivo pela web e está disponibilizada na página do projeto Lente Quente no Facebook.
} 
no gesto de olhar a realidade e reelaborar a paisagem cultural; (b) escalas de produção do documentarismo fotográfico ou de uma certa e possível 'geografia do fotojornalismo'; (c) marcas de uma modulação, posição ou concepção específica da fotografia na documentação e eventual transformação da realidade social.

Para se contornar tais objetivos amplos, deve-se procurar, na exposição do fotógrafo sobre o próprio trabalho, marcas de uma cultura jornalística capaz de agregar um modo particular de ver, agir e narrar - conforme orienta a teoria do jornalismo (TRAQUINA, 2005). As pistas sobre o 'funcionamento' da captura fotográfica empenhada seriam, nesse sentido, vitais para a percepção da articulação das competências de reconhecimento, procedimentais e discursivas (GUERRA, 2003) num 'simples' gesto fotográfico. Pressupõe-se um saber de ação reivindicado e desenvolvido no trabalho fotográfico em campo diretamente implicado a um modo seletivo de ver e de enquadrar ou narrar os acontecimentos. Em outros termos, significa abandonar a prerrogativa da mensagem fotográfica e enfatizar a produção de fotos como um gesto cultural $^{2}$ - caro ao enclave da cultura jornalística, marcada por um modo específico de ver, agir e falar que estrutura um repertório comum de valores e referências. Sendo que, no ato fotográfico, as três competências se fazem presentes e vão ser acionadas também ao longo do processo produtivo, em graus variados.

Outra justificativa para se relembrar a palestra de Ripper e se analisar esse tipo de material ou fala é a de que é possível reconhecer uma dimensão da produção jornalística que reside nas suas bordas, num âmbito de trocas e contatos que circunda e perfaz a elaboração noticiosa propriamente dita. Isso parece válido também ao fotojornalismo. Muitas vezes, em encontros fortuitos ou organizados, formais ou informais, acontece um tipo particular de aprendizado um tanto horizontalizado e recíproco da fotografia. Aí circula, de modo brando e nem sempre sistemático, um saber específico do mundo da fotografia constituído por histórias, lendas, orientações, recomendações, reconstituições, afetações, representações de si e dos outros, proto informações e indícios de um modo de fazer, de um artesanato (MILLS, 2009) ou algo na lógica do artífice (SENNETT, 2009).

As reuniões mais ou menos espontâneas entre praticantes da fotografia fazem transitar referências nem sempre escritas, geram trocas e saberes apreendidos na presencialidade, de modo franco e difuso. Trata-se de um espaço 'clandestino' rico em possibilidades de aprendizado e de inserção na cultura do fotojornalismo. No caso de palestras sobre fotografia, há uma certa previsibilidade no evento - em geral, inicia-se uma explanação sobre tema ou ponto

\footnotetext{
${ }^{2}$ Essa tensão ou crise entre a perspectiva cultural e informacional das interações sociais com a entrada em cena dos meios de comunicação de massa (como o cinema, mas também a fotografia) foi evidenciada por Benjamin (1996) naquilo que se pode entender como disputa entre os protocolos da informação e da narração. O clássico texto permite reconhecer, nesse jogo de oposições, características e potencialidades dessa dimensão da experiência humana como história, narrativa, e não 'apenas' informação (transmissão). Mais do que um apagamento direto de um pelo outro numa suposta linha evolutiva, o que se tem é o reconhecimento da envergadura cultural dos gestos de comunicação midiática, colocando em crise e transformação os protocolos tradicionais da interação humana e social.
} 
de vista, seguida da exposição comentada de fotos (já um indício da impossibilidade de separar, em fotografia, o conhecimento do ato de produzir/descrever imagens, realizar capturas, deslocar-se pela realidade, perambular pelo mundo e ver/registrar tais e tais coisas). Ao final, abre-se para trocas com o público - no caso específico, composto por estudantes e professores do curso de Jornalismo, professores de outras áreas envolvidos na organização do evento e também profissionais da fotografia que atuam em Ponta Grossa.

Desse modo, o mundo profissional da fotografia oferece, em tais eventos ou reuniões, uma representação do que configura o seu modo de fazer. E essa representação, nos termos de Becker (1997), opera seleções, exclusões, arranjos e ênfases sobre elementos específicos numa espécie de narrativa organizada - que agora se quer conhecer melhor, nesse esforço de recapitulação da participação de Ripper em evento na UEPG. Afinal, toda representação de uma atividade social é constrangida por circunstâncias específicas, a saber.

Esse tipo de atividade, como ciclos de debates ou fotoclubes e cineclubes, possui uma dívida justamente com certa mobilização estudantil e transformação da vida universitária e cultural em voga nos anos de 1960 em alguns países da Europa, culminando em maio de 1968. Entre as marcas do período estão a chegada ao espaço universitário de populações até então não contempladas pelo sistema de ensino exclusivista, com muitas pessoas vindas da zona rural a reivindicar a ampliação do acesso à universidade e aos espaços de formação (o que passava também por ampliar o número de cadeiras e o tamanho das salas de aula). Fato esse que impacta diretamente a figura da autoridade de saber constituída.

No final da década de 1960, um em cada sete jovens italianos estava na universidade (dez anos antes, a proporção era de um para vinte). $\mathrm{Na}$ Bélgica, era de um para cada seis. Na Alemanha Ocidental, onde, em 1950, havia 108 mil estudantes, e onde as universidades tradicionais já começavam a sofrer os efeitos da superpopulação, havia quase $400 \mathrm{mil}$ alunos no final dos anos 60. Na França, o número de universitários em 1967 se igualava ao de secundaristas em 1956. Por toda a Europa, o contingente estudantil era mais elevado do que nunca - e a qualidade da experiência acadêmica se deteriorava rapidamente. Tudo vivia lotado: bibliotecas, dormitórios, salas de aula, refeitórios. As instalações eram sofríveis, inclusive nas que eram novas. (JUDT, 2007).

Do mesmo modo que são fortes as imagens utilizadas na descrição anterior do historiador, são emblemáticas como documentação e reportagem desse período as fotos do fotógrafo alemão Michael Ruetz, reunidas na exposição '1968 - Tempos Incômodos'. Um dos registros mostra manifestos no campus da Universidade Livre, em Berlim, em 1967, após assassinato de Benno Ohnesorg. Faixa, cartaz, megafone, manifestantes com o braço erguido, com o fotógrafo em meio à plateia - materializando duas características desse trabalho de Ruetz: o apreço pelo coletivo e pela proximidade em relação à cena fotografada (SCHOENHERR, 2012). 
Em outra foto, de 21 de outubro de 1967, o protesto nas ruas de Berlim é contra a guerra dos Estados Unidos no Vietnã. Manifestantes de braços dados marcham em direção à câmera do fotógrafo. Já o registro do início de novembro do mesmo ano mostra o ato de fundação da Universidade Crítica, também na capital alemã, com auditório lotado, repleto de mãos para cima. Um contraste e tanto para com a foto de 2 de julho de 1968, em que se vê uma sala de aula vazia, mas revirada, cadeiras derrubadas, prateleiras de livros ao fundo e um manifesto no quadro. Trata-se da ocupação estudantil do Instituto de Nipologia da Universidade Livre, em Berlim. A foto de 25 de agosto de 1968 mostra manifestos nas ruas de Praga.

É fácil saltar dessas imagens para o famoso registro do checo Josef Koudelka, que mostra o relógio de pulso do fotógrafo a testemunhar o exato momento em que se dá a invasão da Tchecoslováquia, um fragmento do que veio a ser chamado Primavera de Praga. E dessas fotos pode-se passar num piscar de olhos para o epicentro da eclosão estudantil nos cenários de Paris que ficaram imortalizados nas fotos de Bruno Barbey: manifestantes atacam policiais franceses no bulevar Saint-Germain; estudantes ocupam o pátio da Universidade de Sorbonne; carros incendiados e virados na rua Gay-Lussac; estudantes dormem em um anfiteatro na Sorbonne ${ }^{3}$. Esses conjuntos levam a transitar por imagens de Robert Lebeck (que já disse em entrevistas que, se dependesse dele, o maio de 68 não teria acontecido), sugestivas sobre certa ebulição comportamental nos anos 60 na Itália, no continente africano, na Espanha e na Rússia. As manifestações de rua aqui não estão em primeiro plano. Ainda assim, existe uma contiguidade entre essas zonas em foco, entre seus referentes, uma partilha de atualidade, talvez. Todos muito próximos, ainda, do núcleo gerador do maio de 68 como acontecimento4. Para ampliar essas reverberações seria preciso perambular, chegando ao Brasil, pelas fotos de Evandro Teixeira das reações à ditadura civil-militar e ao AI-5 (há exatos 50 anos!), entre seus registros mais famosos e utilizados até hoje em ciclos de análise e discussão do período no país. Em comum, no mínimo, a manifestação de rua como signo principal e evidência corporal do conflito de protagonismo estudantil.

João Roberto Ripper começa a trabalhar no jornalismo nos anos de 1970, dando sequência à geração de Evandro Teixeira. Passa a organizar a categoria de repórter fotográfico no Brasil, conquistando o reconhecimento do direito autoral sobre as imagens produzidas e a menção aos créditos das fotos nos jornais. Nos anos de 1980, participa da organização da cobertura fotográfica dos movimentos de rua das "Diretas Já!" por eleições livres e voto popular em várias cidades do país. Nos anos 90, cria o centro de documentação 'Imagens da Terra', assumindo a partir daí posição mais evidente como documentarista.

Por isso, sugere-se trabalhar com a 'ideia 1968' mais como 'eco visual' ou reverberações amplas e múltiplas - na linha da proposta de Dyer (2008) - do que na sua dimensão de evento

\footnotetext{
${ }^{3}$ Meio século depois, o fotógrafo retorna aos mesmos cenários e faz uma comparação: https://brasil.elpais.com/brasil/2018/04/18/album/1524051270_015115.html\#foto_gal_17

${ }^{4} \mathrm{~A}$ possibilidade de abordar tal evento pela ótica do acontecimento gerou debate específico no Ciclo 50 anos em Movimentos.
} 
histórico, superando relações de causalidade, igualmente. Isso permite caminhar pela relação entre fotos, trabalhos, momentos da produção, em busca de convergências e singularidades, percebendo áreas de continuidade. A hipótese é de que a atuação de um fotógrafo constitui-se como espaço múltiplo e de simultaneidades a articular diversas atualizações e zonas de convergência que modulam o olhar fotográfico sobre a paisagem cultural (SCHOENHERR, 2017). $\mathrm{Na}$ linha de pensamento de Massey (2012), é preciso também entender o espaço fotográfico como um espaço que possui tempo e como um tempo que possui espaço.

\section{UM PROJETO FOTOGRÁFICO QUE REFLETE SOBRE O PROCESSO PRODUTIVO}

O convite ao fotógrafo para a palestra foi feito pelo projeto Lente Quente. A ação extensionista, ofertada desde 2010, agrega de dez a quinze estudantes das quatro séries do curso e funciona, frente a esse tipo de demanda (organização de evento), como uma espécie de fotoclube, incluindo profissionais convidados em seu círculo de interlocuçãos. Nos demais momentos, a iniciativa assemelha-se a uma rotina produtiva de redação ou agência de foto especializada em cultura, como já assinalamos em outro momento, resguardado o caráter de aprendizado inerente ao espaço (HONORATO; SCHOENHERR \& MOABIS, 2018).

Essa tática de mesclar o ritmo de produção com momentos mais brandos de organização de falas, oficinas ou exposições permite, gradativamente, que o grupo amplie a roda de conversa sobre fotografia em momentos oportunos - numa interface com a comunidade profissional, estratégia vital para trocas, aprendizados, contatos e conversações que, ao que tudo indica, voltam a dar o tom de uma certa reorganização ou retomada de fotoclubes pelo país, como se tem assinalado (de modo polêmico em relação ao papel das redes digitais) ${ }^{6}$.

O primeiro contato do projeto Lente Quente com João Roberto Ripper se deu em Curitiba, no espaço "Caixa Cultural", em 22 de fevereiro de 2011, por ocasião do lançamento do livro Imagens Humanas - trabalho que congrega anos de documentarismo fotográfico do autor. Já naquele momento, chamou atenção dos participantes do projeto a capacidade do fotógrafo de trabalhar com sobras, penumbras e sua posição de respeito em relação à luz natural dos ambientes. Ripper participou de bate papo com o professor Dante Gastaldoni, da Universidade Federal Fluminense, com quem desenvolveu a Escola de Fotógrafos Populares, no conjunto de favelas da Maré, o maior do Rio de Janeiro. A partir desse contato inicial, o livro e as fotos de Ripper se transformaram numa espécie de 'referência obrigatória' aos estudantes

\footnotetext{
${ }^{5} J a ́$ participaram como palestrantes ou oficineiros convidados os fotojornalistas Henry Milleo, Rodrigo Czecalski, Marco Favero, Marcelo Andrade, Celso Margraf, Maykon Lammerhirt, além dos fotógrafos Andressa Marcondes, Fábio Ansolin, Cássio Murilo e Nicolas Salazar.

${ }^{6} \mathrm{~A}$ esse respeito, conferir duas versões para o fenômeno da possível retomada dos fotoclubes em https://www1.folha. uol.com.br/ilustrissima/2018/07/com-concursos-e-difusao-de-imagens-redes-sociais-dao-folego-a-fotoclubismo.shtml e https://www1.folha.uol.com.br/ilustrissima/2018/06/essenciais-para-elevar-fotografia-a-arte-clubes-tem-futuro-incerto.shtml.
} 
ingressantes no projeto de extensão, conversas esparsas por e-mail foram entabuladas desde então. Curiosamente, sete anos depois, parte da palestra do fotógrafo na UEPG se baseou na exposição das fotos de seus ex-alunos da Maré, agora alçados à condição de fotógrafos e fotógrafas de destaque, como profissionais a imprimir um novo olhar sobre as comunidades (e o país) onde vivem. "Hoje são mais de 60 fotógrafos vivendo da fotografia" (RIPPER, 2018)7, destacou na palestra. Novamente, tem-se aqui - nesse ímpeto de ampliar o âmbito da formação popular em fotografia, socializar o conhecimento e romper com amarras exclusivistas da academia - uma possível reverberação de 1968, nesse repensar o papel das universidades e sua articulação à produção cultural popular (como aconteceu no Brasil, muito por ação de movimentos sociais, culturais e estudantis). Algo a tensionar o horizonte da extensão universitária como um efetivo diálogo e prestação de serviço à comunidade onde a instituição está inserida.

\section{LEMBRANÇAS OU “QUASE-MEMÓRIA" DO DIA 26 DE JUNHO DE 2018}

Ripper saiu do Rio de Janeiro, desembarcou em Curitiba e chegou a Ponta Grossa no fim da manhã do dia 26 de junho. Almoçou com professores e estudantes do projeto que o aguardavam. Mostrou-se animado com uma experiência recente de oficina fotográfica no Uruguai, num método que abordaria mais tarde na palestra e que atrai cada vez mais sua atenção - voltado ao que chama de bem querer e de afeto. Ao longo do almoço, falou das conversas com o motorista da universidade que o trouxe da capital, relembrou personagens de viagens ao Rio Grande do Sul, numa postura sempre atenta aos pequenos contatos cotidianos, a identificar sujeitos de suas histórias. Em reação ao noticiário da TV, ainda no restaurante, mostrou-se preocupado com a situação do país e recomendou o documentário 'O Processo' aos estudantes. Retirou-se então para o hotel para descansar e ver o jogo entre Argentina e Nigéria pela Copa do Mundo. Mais tarde, pouco antes da palestra, concedeu entrevista nos estúdios da TV Educativa. No percurso, pareceu bastante animado com experiências de comunicação popular, tal como o jornal Candeeiro, exemplo que iria repetir mais tarde. Nesses interstícios, Ripper não é o tipo de fotógrafo que conversa sobre câmeras e equipamentos, também não fala muito sobre suas fotos. Prefere lembrar de pessoas e histórias que encontra pelo caminho, num tipo de encanto pelo comum, pelas pequenas lutas cotidianas daqueles a quem não é dado o direito de se expressar e de ser visto. Um tipo de política do cotidiano que reverbera a década de 1960 e agora se reinventa. A palestra da noite seguiu nesse tom.

Ripper define seu trabalho como fotografia em defesa dos direitos humanos. Depreendese da apresentação que a ideia do que sejam os direitos humanos advém não do campo conceitual (tampouco do jurídico ou do político), mas das situações fotografadas, dos locais visitados, das realidades conhecidas ou a conhecer, dos trajetos e deslocamentos empreendidos para

${ }^{7}$ Todas as referências a Ripper (2018) a partir de agora remetem à palestra do dia 26 de junho de 2018, na sala A17, no Campus Central da UEPG. 
capturas fotográficas, dos encontros com as pessoas e seu entorno, da escuta de suas histórias. Esse inventário ou essa empresa empírica é que 'recorta' e melhor define o tema dos direitos humanos em foco no trabalho do autor - numa tática muito marcada dos empreendimentos do documentarismo, esse movimento indutivo e inferencial de conhecimento da realidade.

O tema direitos humanos se traduz, nas fotos, em imagens de condições de trabalho, conflitos agrários, acesso à saúde, populações tradicionais, comunidades ribeirinhas, quilombolas, indígenas, mulheres, entre outros. As fotos reportam-se a situações de trabalho escravo, trabalho infantil, acesso desigual à terra, seca, desigualdade social, racismo, impactos da monocultura e dos latifúndios, trabalhadores de carvoarias, entre outras cenas. Essa variedade de motivos dentro do tema geral articula-se à abrangência do trabalho do autor, pois se trata de um olhar sobre o país, num percurso em direção ao interior profundo, para além dos centros urbanos e de poder ou de visibilidade.

Apenas durante a palestra, o fotógrafo citou situações e mostrou fotos de 11 estados brasileiros onde esteve: Rio de Janeiro, Alagoas, Rio Grande do Norte, Amazonas, Pará, Minas Gerais, Mato Grosso do Sul, Paraíba, Maranhão, Pernambuco e Tocantins. O percurso documental de Ripper opera, assim, muito em sintonia com o livro Imagens Humanas, numa 'escala país' de dimensões quase continentais. Seria possível dizer algo semelhante a respeito do acervo de Evandro Teixeira, vale lembrar.

Nesses termos, mobilizar a fotografia em defesa dos direitos humanos significa perceber traços em comum nas situações que encontra em todas essas diferentes realidades um tanto invisíveis, mas também atentar para as singularidades, para histórias que são únicas, e aí lançar luz. Isso tem a ver com a estratégia de combinar, na abordagem um tanto jornalística e assumidamente documental que faz dos direitos humanos, a postura de indignação com as realidades a uma procura pela beleza e pela sensualidade nas mais difíceis situações.

Quando a gente consegue mostrar as belezas dos fazeres, a gente aproxima as pessoas fotografadas, filmadas ou entrevistadas, das pessoas que vão poder ver a informação. Essa para mim é a premissa fundamental. $\mathrm{Eu}$ acho que um documentarista nunca pode perder a capacidade de se indignar com as injustiças, mas principalmente, numa pode perder a capacidade de se maravilhar com as pessoas que ele fotografa e com as belezas que ele encontra. (RIPPER, 2018).

Percebe-se pela exposição do fotógrafo que a competência de reconhecer fatos dignos de nota e registro fotográfico na área dos direitos humanos num campo de trabalho do tamanho do Brasil (esse modo específico de ver o mundo, atentar para certas realidades e não outras) depende, em grande medida, de variáveis que preenchem uma competência de ação particular, um modo de agir calcado em determinadas técnicas e numa certa ética profissional. Existem habilidades e procedimentos acionados em terreno, na abordagem dos personagens e das situações, no contato ou encontro com os fotografados e demais intermediários do processo documental. 
Um desses princípios que se converte em procedimento produtivo e de ação é a horizontalização das relações, a ruptura de hierarquias entre fotógrafo e fotografados. Nesse processo de reciprocidades, as duas partes aprendem algo e podem ensinar: "Quando se vê de igual para igual uma pessoa, você está aberto a ver as belezas e se maravilhar com o que ela faz, com o terçado que ela faz, com a forma que ela pesca, como ela acredita na história do homem do rio, na história das mulheres do rio, dos curumins" (RIPPER, 2018). Nesse tipo de técnica, recomenda-se fotografar pouco, observar, conversar e escutar as histórias. Trata-se de uma captura fotográfica mais lenta do que aquela da prática jornalística de mercado em ritmo diário: "Dá tempo ao tempo que o tempo se volta a teu favor" (RIPPER, 2018).

Em várias passagens relatadas durante a palestra, o fotógrafo ressalta a necessidade que sentiu de ficar mais tempo junto a comunidades para ver mais, aprender mais, esperar o momento certo: "vai ter um momento em que a pessoa está delicada, ela está tentando acertar" (RIPPER, 2018). Outra característica do trabalho documental do autor é (em alguns casos) passar décadas dedicado a certas realidades - Ripper fotografa populações tradicionais há 30 anos, por exemplo.

Esse desempenho baseado na observação, na conversa, na escuta e num ritmo fotográfico mais lento modifica, por sua vez, as competências de reconhecimento anteriores permitindo aguçar o modo de ver ou perceber camadas de sentido dentro dos temas e das situações. O fotógrafo revela sempre encontrar vários trabalhos dentro de um trabalho, o que tem muito a ver com o registro documental de capturar variações dos fenômenos num acervo iconográfico mais amplo: "Eu acho que dentro de um trabalho de um quilombo tem a negritude, tem o velho que tem o saber e uma coisa forte, vários rostos de crianças. Eu faço vários trabalhos dentro dos trabalhos que eu faço" (RIPPER, 2018). Na abordagem que fez da realidade de mulheres, também destaca a capacidade de perceber desdobramentos temáticos sobre o universo feminino a partir de diferentes tipos de situação, como mulheres que moram sozinhas, com os filhos, com os companheiros ou companheiras, com os maridos e os filhos, que cuidam da avó, da irmã.

Seria essa articulação entre modos de ver/reconhecer e uma competência de ação que molda um ponto de vista ou um modo de narrar tais realidades diferentes das ofertas midiáticas marcadas pelo que chama de "história única" (RIPPER, 2018), pelo reforço dos poderes e do estereótipo.

O estereótipo está diretamente ligado ao poder dos poderes federais, estaduais, municipais, poderes do grande capital, da indústria e do comércio. Esses poderes ditam e dizem: você é isso. Que tática usam? Justamente a edição da beleza dos fazeres dessas populações menos favorecidas. Quando você conta uma história única você quebra a dignidade da pessoa, afasta a pessoa de quem recebe a notícia e afasta de uma forma tão brutal que às vezes muda aquela realidade, aumenta o 
processo de violência e muda não só de uma pessoa, de uma comunidade, mais muitas vezes, de um país e atinge até continentes. (RIPPER, 2018).

Fica evidente no discurso do fotógrafo sobre seu trabalho esse caráter relacional e de contraposição a outros espaços de mídia (uma espécie de crítica de mídia), tendo como iniciativa privilegiada, nesse sentido, a produção dos fotógrafos populares da Maré. "Quando as pessoas começaram a se ver publicadas de uma forma onde apareciam potencialmente criminosas, começaram a gritar que eram diferentes, queriam mostrar que eram diferentes e começaram inúmeras experiências no campo, nos quilombos, nas áreas semiáridas e nas favelas" (RIPPER, 2018).

O ponto de vista em questão é posicionado de modo relacional, tanto por aquilo que dá a ver como pela posição que assume para conseguir ver, para efetuar a captura fotográfica - trata-se de uma perspectiva "de perto e de dentro", como sugere Magnani (2016) sobre a etnografia urbana. Daí a necessária proximidade para com moradores e moradoras. Ripper mostra uma foto do Piscinão de Ramos: "Só sai sujo e feio, às vezes ele é sujo e feio. Como Capacabana às vezes está suja e feia, Ipanema, Leblon. E aí o olhar de um morador que fez o seu trabalho sobre o Piscinão (de Ramos) e as pessoas que moravam no entorno, uma das fotos é essa aí" (RIPPER, 2018). Retoma esse ponto em outro momento ao criticar a história única de violência nas favelas e sugere trocar o ponto de vista, e novamente recomenda: "Começa a contar a história de um conflito em uma favela a partir da história de um pai que está segurando seu filho, protegendo, apavorado, e você vai ter outra história sobre o conflito" (RIPPER, 2018).

Essas particularidades dos modos de ver e agir (expressões dos saberes de reconhecimento e procedimental) também encontram ressonância nas competências narrativas ou discursivas e, mais precisamente, na forma como Ripper tem finalizado os materiais e previsto a circulação das fotografias. Uma das marcas que diferencia o processo é a adoção do que tem chamado de foto compartilhada. Trata-se de um tipo de abertura do processo produtivo e de acabamento fotográfico às interferências e decisões das comunidades fotografadas. Significa que as pessoas fotografadas têm a chance de selecionar e excluir as fotos realizadas, ou seja, participam ativamente das decisões de edição e publicação. Outro aspecto desse método reforçado pelo fotógrafo é o retorno dado às comunidades fotografadas, que recebem um pendrive do autor com cerca de 200 fotos, podendo fazer exibições públicas. Nas ocasiões em que as fotos produzidas são vendidas, o autor preza pela divisão dos lucros com as pessoas fotografadas. Interessante imaginar o quanto esse conjunto de estratégias promove um tipo de desmontagem da programação da câmera fotográfica ou da caixa preta, como sugere Flusser (1985).

Por fim, cabe salientar que é uma determinada capacidade técnica, envolvida numa cultura profissional jornalística e de envergadura documental (e suas respectivas competências aqui descritas ou recuperadas), que permite que várias fotos de Ripper sirvam efetivamente como denúncia e defesa dos direitos humanos num país como o Brasil - um lugar de doenças esquecidas pelo poder público; de mulheres doadas enquanto crianças por seus pais e depois 
violentadas, quando adultas, por seus patrões; de índios desaldeados; de populações tradicionais ameaçadas pela monocultura; de trabalho escravo em carvoarias; de trabalhadores mortos por pistoleiros no campo, onde vigora uma tabela de preços para matar, entre outras situações descritas durante a palestra e expostas nas imagens do autor. O discurso de transformação política não se faz dissociado de uma competência técnica expressiva, como já sugeria Benjamin (1996) aos escritores. Ripper (2018) relembra do registro que fez do massacre de Eldorado dos Carajás, quando trabalhadores rurais sem terra foram assassinados: "Foi uma das coisas mais fortes que fotografei. As fotos serviram como prova contra o Governo do Estado do Pará e contra a PM. A maioria desses trabalhadores foram mortos depois de baleados". Do mesmo modo, seus trabalhos servem de denúncia a organismos internacionais, como a Organização Internacional do Trabalho e Unicef. Esse poder de denúncia resulta de uma técnica capaz, inclusive, de reconhecer a dignidade em contextos de opressão e o afeto entre os mais pobres.

\section{DEPOIS DE 50 ANOS EM MOVIMENTOS, SIGAMOS!}

A proposta do Ciclo Comemorativo 50 anos em Movimentos deu luz a acontecimentos que são, ainda hoje, significativos para qualquer proposta de intervenção social. Mais que uma lembrança daquilo que esteve em maio de 68, o evento também oportunizou as reverberações daquele momento histórico. A vida profissional do fotógrafo João Roberto Ripper é uma dessas ligações com o maio de 68. O trabalho dedicado ao registro e documentação de questões de diretos humanos se apresenta como uma possibilidade de acessar o espírito das motivações dos movimentos sociais na atualidade.

A visita do documentarista a Ponta Grossa representa mais que uma ligação como os movimentos de maio de 68 , e sim uma chance de atualizar a proposta de intervenção social que estava presente naquele momento histórico. A presença (majoritariamente) de jovens no evento realizado no Campus Central da UEPG indica que a história se constrói a partir da renovação do passado, pelo conhecimento daquilo que aconteceu ontem e que, de alguma forma, estará à nossa frente.

Certamente, o relato apresentado neste documento não consegue dar conta das diferentes apropriações que os participantes fizeram da palestra, mas, na forma de uma "quase-memoria", tentou trazer a percepção das contribuições deixadas por uma das figuras mais significativas para o fotodocumentarismo no Brasil. O conteúdo completo da palestra também foi registrado em vídeo e pode ser acessado pelo endereço: https://www.facebook.com/ lentequente/videos/1778724758879339/

\section{REFERÊNCIAS}

BECKER, H. Métodos de pesquisa em ciências sociais. São Paulo: Hucitec, 1997. 178p. 
BENJAMIN, W. Magia e técnica, arte e política. Trad: S.P, Rouanet, São Paulo: Braziliense, 1996. DYER, G. O instante contínuo: uma história particular da fotografia. São Paulo: Companhia das Letras, 2008. 293p.

FLUSSER, V. Filosofia da caixa preta: ensaios para uma futura filosofia da fotografia. São Paulo: Hucitec, 1985. 48p.

GUERRA, J. L. O nascimento do jornalismo moderno: Uma discussão sobre as competências profissionais, a função e os usos da informação jornalística. XXVI Congresso Brasileiro de Ciências da Comunicação, Minas Gerais, 2003.

HONORATO, S; SCHOENHERR, R; MOABIS, M. Seminário de Inverno de Estudos em Comunicação da Universidade Estadual de Ponta Grossa. Paraná, 2018.

JUDT, T. O espectro da revolução. Revista Piauí, ed. 8, maio de 2007. Disponível em: https:// piaui.folha.uol.com.br/materia/o-espectro-da-revolucao/

MAGNANI, J. G. C. De perto e de dentro: notas para uma etnografia urbana. Revista Brasileira de Ciências Sociais, vol. 17, n. 49, p. 11-29, jun. 2002. Disponível em: http://www.scielo.br/pdf/ rbcsoc/v17n49/ao2v1749.pdf. Acesso em: 5 ago. 2016.

MASSEY, D. Pelo espaço: uma nova política da espacialidade. Rio de Janeiro: Bertrand Brasil, 2012.311p.

MILLS, C. W. Sobre o artesanato intelectual e outros ensaios. Rio de Janeiro: Jorge Zahar, 2009.

RIPPER, J. R. Fotografia de Resistência: Imagens em defesa dos Direitos Humanos. Palestra na Universidade Estadual de Ponta Grossa em 26 de junho de 2018. Transcrição de Saori Honorato e Veridiane Parize.

SCHOENHERR, R. A imagem da música no espaço público em Ponta Grossa (PR) de 2010 a 2014: Implicações geográficas do fotojornalismo cultural. Tese apresentada para obtenção do título de Doutor em Geografia na Universidade Estadual de Ponta Grossa, Programa de Pós-Graduação em Geografia, curso de Doutorado em Geografia, 2017.

SCHOENHERR, R. Tempos de incômodos desafios. Observatório da Imprensa, 11 set 2012, ed. 711. Disponível em: http://observatoriodaimprensa.com.br/feitos-desfeitas/ed711-temposde-incomodos-desafios.

SENNETT, R. O artífice. Rio de Janeiro: Record, 2009. 360 p.

TRAQUINA, N. Teorias do jornalismo: a tribo jornalística - uma comunidade interpretativa transnacional. Florianópolis: Insular, 2005. 216p.

Recebido para publicação em 20 de nov. de 2018. Aceito para publicação em 1 de maio de 2019. 